\title{
Effect of Frustration Intolerance and Emotional Maturity on Internet Addiction among Young Adults
}

\author{
Research Article
}

Volume 1 Issue 1- 2020

\begin{abstract}
Author Details
Soni Kewalramani* and Shambhavi Pandey

Department of Psychology, Amity University, India

*Corresponding author

Soni Kewalramani, Assistant Professor, Department of Psychology, Amity University, Lucknow, India

Article History

Received: September 30, 2020 Accepted: November 30, 2020 Published: December 07, 2020
\end{abstract}

\begin{abstract}
The growth of internet usage has been exponential. There are currently 4.54 billion active internet users in present time. The internet was originally designed to facilitate the communication of information within academia and military. But despite the benefits there is growing evidence that the internet is adversely affecting the mental health and well-being of users. Internet provides immediate reinforcement, when facing stressful events in daily life, beliefs of frustration intolerance may make adults unwilling to tolerate negative emotional events and may make users to escape from the unacceptable frustrations of daily life and seek immediate gratification from the internet. The present study focuses on the effect of frustration intolerance and emotional maturity on internet addiction among young adults. It was observed that both the frustration intolerance and emotional maturity have an effect on internet addiction. Further, this impact of both the variables on male and females and differences in their mean was observed through t-test.
\end{abstract}

Keywords: Mental health; Internet addiction; Frustration intolerance; Emotional regression, Social maladjustment, Personality disintegration

\section{Introduction}

The present research focuses on the frustration intolerance belief and emotional maturity. The frustration intolerance is measured through four dimensions i.e., emotional intolerance, entitlement, discomfort intolerance and achievement. And the emotional maturity is measured through five factors known as emotional unstability, emotional regression, social maladjustment, personality disintegration, lack of independence. The effect of frustration intolerance and emotional maturity on internet addiction in young adults has been studied.

\section{Frustration intolerance}

The term frustration intolerance belief are hypothesized Rational Emotive Behaviour Therapy (REBT), according to this approach the inability to tolerate frustration and discomfort is a core feature of psychological disturbance [1]. Frustration intolerance represents a demand that reality should be how we want it to be. Frustration intolerance is synonymously used with the term discomfort disturbance. More importantly, these terms are used in the REBT literature to refer to a range of different content areas, such as intolerance of emotional discomfort, uncertainty, and frustration [2]. Frustration intolerance beliefs are considered to be one of the fundamental categories of irrational beliefs. REBT recognizes two basic categories of disturbance-"ego disturbances" and "discomfort disturbances". Ego disturbances arise from the belief that one's selfworth depends on meeting certain absolutistic demands. Discomfort disturbances are based on the belief that one 'cannot stand' having unmet demands, and a refusal to accept the reality of frustration and discomfort. These two belief processes are assumed to partly interact, but also to have an independent and differential relationship with dysfunctional emotions and behaviour. Thus, two subtypes of emotional disturbance are hypothesized-ego and discomfort.

\section{REBT concept of frustration intolerance}

The concept of frustration intolerance also has roots in Psychoanalysis, with the work of Karen Horney (1950) of particular relevance to REBT theory. She argued that, unlike wishes, neurotic "shoulds" were "irrational" because they "assume a right, a title, which in reality does not exist" (p. 42). Many of the beliefs described by Horney, such as "life should be easy, painless, and effortless". However, there are important differences between Horney's model and that of REBT. For Horney, shoulds reflect a discrepancy between the "real" and the "ideal" self, whereas REBT argues that frustration intolerance beliefs are distinct from those of self-worth.

REBT proposes that frustration intolerance beliefs are distinct from those regarding the self. Ellis [1] initially described these two categories as ego disturbance and discomfort disturbance and defined 
them in terms of their overall belief content. Thus, frustration intolerance referred to the demand for comfort and gratification, and ego disturbance to the demand that one must perform well, or gain approval, to achieve self-worth. More generally, it has been proposed that self-worth and frustration intolerance are characterized by different types of cognition [3]. Thus, frustration intolerance represents the belief that reality should be how we want it to be, whilst ego disturbance is based on a definition of self-worth as dependent on meeting certain conditions.

REBT proposes that frustration intolerance beliefs are distinct from those regarding the self. Ellis [4] initially described these two categories as ego disturbance and discomfort disturbance and defined them in terms of their overall belief content. Thus, frustration intolerance referred to the demand for comfort and gratification, and ego disturbance to the demand that one must perform well or gain approval to achieve self-worth. More generally, it has been proposed that self-worth and frustration intolerance are characterized by different types of cognition (Di Giuseppe 1996; Rorer 1989). Thus, frustration intolerance represents the belief that reality should be how we want it to be, whilst ego disturbance is based on a definition of selfworth as dependent on meeting certain conditions.

\section{Frustration Intolerance as an Irrational Belief}

The theory that rational and irrational beliefs are important elements in emotional and behavioral disturbance. Irrational beliefs lead to dysfunctional, disturbed emotions. Irrationality refers to that which is rigid and extreme, prevents people from achieving their basic goals and purposes, is illogical and is empirically inconsistent with reality.

\section{Dimensions of Frustration Intolerance}

Research suggests it is a multidimensional construct described by four factors: Discomfort intolerance (which concerns the belief that life must be easy, comfortable, and without problems), entitlement (which concerns the belief that own desires must be met and that others must not hinder them), emotional intolerance (which concerns the belief that emotional distress is intolerable and must be quickly removed or avoided), and achievement frustration (which concerns the belief that we must achieve our goals without obstruction).

\section{Entitlement}

Entitlement reflects the belief that desires must be met, and that other people should indulge and not frustrate these desires (e.g., "I can't stand criticism, especially when I know I am right"). As previously noted, this consists of two facets: Fairness (e.g., "I can't tolerate being taken for granted") and immediate gratification (e.g., "I can't stand having to wait for things I would like now"). Entitlement is closely associated with the concepts of justice, fairness, deservedness, and rights. Evidence suggests that it is perceived injustice, rather than actual deprivation, that is central to the experience of anger and intolerance, and this perception is based on entitlement (Martin,1986). Thus, disrespect is perceived as unfair because the person believes they are entitled to better treatment.

\section{Emotional Intolerance}

REBT has long emphasized the importance of emotional intolerance, particularly in terms of secondary disturbance, such as anxiety about anxiety [5]. The GABS includes, within a single "comfort" factor, items referring to both emotional intolerance and intolerance of everyday discomfort. However, on the FDS these formed separate factors, with emotional intolerance items reflecting the belief that emotional distress is intolerable and must be avoided or controlled, and uncertainty reduced.

\section{Discomfort Intolerance}

Frustration intolerance has also traditionally been defined in terms of demands for a comfortable life. Indeed, acting in spite of shortterm discomfort in order to obtain long-term benefits is central to the concept of frustration intolerance. Discomfort intolerance represents the belief that life should be easy, comfortable, and free of hassles and effort. These beliefs play an important role in a range of psychological problems, particularly over the longer-term. Therefore, discomfort intolerance beliefs would be expected to be important in chronic depression, and indeed this problem is associated with higher levels of avoidant coping [6].

\section{Achievement Frustration}

Intolerance of frustrated goals is clearly related to perfectionism, although opinions are divided as to the nature of perfectionism. It has been argued that perfectionism is defined, not by high standards per se, but by self-worth being made contingent on meeting these standards [7]. However, perfectionism scales do not clearly distinguish between frustration intolerance perfectionism and self-worth perfectionism, or between demands and preferences for high standards [8]. REBT theory suggests that demands for high standards may reflect either frustration intolerance or self-worth.

\section{Emotional maturity}

a. Emotions: Emotions is defined as the "feeling" aspects of consciousness, characterized by three elements: - A certain physical arousal.

- A certain behavior that reveals the feeling to the outside world, and an inner awareness of feelings. (Saundra K. Ciccarelli, 2012)

b. The physiology of emotions: Physically when a person experiences an emotion, an arousal is created by the sympathetic nervous system. The heart rate increases, the pupils dilate, the mouth may become dry and breathing becomes more rapid.

c. Emotional expression: It means the way people behave when they are in the grip of an emotion. Facial expressions, body movements, and actions indicate to others how a person feels.

d. Subjective experience: The third element of emotion is interpreting the subjective feeling by giving it a label: anger, fear, disgust, happiness, sadness, shame, interest, and so on.

\section{Maturity}

The concept of maturity is used in psychology and psychiatry, designates that phase of personality development which corresponds to biological and psychological maturation. We call a person psychologically mature after he has reached a certain level of intelligence and emotional outlook. If the development of a person is undisturbed, biological and psychological maturation progress more or less parallel with each other. Usually, however, biological maturation proceeds ahead of emotional maturation.

\section{Emotional Maturity}

According to Walter D Smitson [9] emotional maturity is a process in which the personality is continuously striving for greater sense of emotional health, both intra-psychically and intra-personally.

Kaplan [10] elaborate the characteristics of an emotionally mature person, say that he has the capacity to withstand delay in satisfaction of needs. He has the ability to tolerate a reasonable amount of frustration. He has belief in long-term planning and is capable of delaying or revising his expectations in terms of demands of situations

L. S. Hollingworth [11] mentions some characteristics of emotionally mature person in the following points:

- He is capable of responding in degree of emotional responses. He does not respond in all or none fashion but Keeps within bounds.

- He is also able to delay his responses as controlled with the impulsiveness of young child.

- Handling of self pity, instead of showing unrestrained self pity, he tries to feel for him. Therefore, emotionally mature is not one who necessarily has 
resolved all conditions that aroused anxiety and hostility but it is continuously in process of seeing himself in clearer perspective, continually involved in a struggle to gain healthy integration of feeling, thinking and action.

Mohsin [12] has developed a Emotional Maturity Scale whereas Rao [13] has adopted Stewart Maturity Scale in Indian Conditions.

Taking these factors into consideration, authors of the emotional maturity scale, prepared a list of Five broad Factors of it:

1. Emotional instability

\section{Emotional regression}

3. Social maladjustment

4. Personality disintegration

5. Lack of independence

\section{Internet addiction}

The concept of internet addiction was presented to a meeting of the American Psychiatric Association [14]. The notion that people could become addicted to the internet was controversial. Today there are some researchers who do not recognize the existence of a specific diagnosis of internet addiction as a psychiatric disorder in its own right [15]. Other researchers maintain the view that any extension of a diagnosis of addiction from one relating purely to the abuse of drugs and alcohol to a group of obsessive behaviors such as eating disorders, exercising, shopping, playing computer games, gambling, and viewing pornographic images trivializes the condition. Despite these reservations, there has been a call for internet addiction to be recognized as a psychiatric disorder [16]. There is also some evidence to support a biological basis to behavioral addictions. Neurological studies have found that the maintenance of substance addiction and behavioral addiction involves stimulation of the same systems in the brain [17], supporting the view that there is a common addictive syndrome. Within internet addiction a number of different types of addiction have been identified, based on

i. Sex (addiction to pornography, pedophilia and adult chat rooms);

ii. Social relationships (online friendships, social networking, chatrooms);

iii. Gambling or trading (compulsive gambling, day trading or auction shopping);

iv. Information seeking (compulsive searching of the web or databases); or

v. Compulsive games playing [18].

However, internet users tend to adopt more than one of the internet addiction types [19].

The growth in use of the internet has been exponential. In 1989 there were around 500,000 internet users [20], whereas today there are over 3.2 billion reported by International Telecom Union and around 560 million users in India (report published by Statista Research Department). Although the internet was originally designed to facilitate the communication of information within academia and the military [21], the technology has received wide usage in the business and leisure domains. Today the internet is accessed by wide sections of the world's population: nationally the highest percentages of people using the internet come from North America (74\%), Australasia (60\%), and Europe (48\%) (IWS, 2008).

Psychological internet addiction would consist in persistent and recurrent nonessential computer/internet behaviors as indicated by five or more of the following during a 6-month period [22]:

a. Preoccupation with the internet (e.g. preoccupation with reliving past on-line activity or planning the next on-line session)

b. Needing to use the internet for an increasing amount of time to achieve satisfaction c. Repeating unsuccessful attempts to control, cutback, or stop internet use

d. Becoming restless, moody, depressed or irritable when attempting to cut down or stop internet use

e. Staying on the internet as a way of escaping problems or of relieving a dysphoric mood (e.g. feelings of helplessness, guilt, anxiety or depression)

f. Staying on the internet longer than originally intended

g. Lying to family members, therapist or others to conceal the extent of the involvement with the internet

h. Breaking the Law or organizational requirement, regulation or procedures to engage with the internet

i. Jeopardizing or losing a significant relationship, job, or educational or career opportunity because of the internet.

\section{Effect of frustration intolerance on internet addiction}

A typical internet addict spends between 40 and 80 hours a week on no work-related internet activity causing a disruption to their sleep patterns, relationships, and physical wellbeing. The "ABCDE" model of REBT, when facing an activating event, the irrational belief will cause the dysfunctional sequence. Frustration intolerance is associated with behavior avoidance as the person says "I can't stand" to an event. And since Internet provides immediate reinforcement such as a feeling of control, synchronous interaction with others, and the freedom of self-representation, when facing stressful events in real life, beliefs of frustration intolerance may make adolescents unwilling to tolerate negative emotional events, and they may be more likely to escape from the unaccepted frustrations of daily life and seek immediate gratification from the Internet and become vulnerable to Internet addiction. since many adolescents experience the Internet early in life, immediate reinforcement provided by the Internet might also influence their beliefs. If pleasure could always be experienced without coping with frustration online, long-term exposure to Internet activity may also make adolescents believe that life should be as comfortable as it is in Internet. Without effective intervention for such beliefs, these adolescents may prefer Internet activity and enter a vicious cycle.

\section{Effect of emotional maturity on internet addiction}

The concept of mature emotional behavior reflects that a person who is able to keep his emotions under control, who is able to delay gratification of needs. A person who has emotional maturity will be able to suffer without self pity. Kaplan and Baron elaborate the characteristics of an emotionally mature person, he may have the capacity to withdraw delay in satisfaction of needs. Whereas emotionally disturbed behavior is described as one who has impulsivity in behavior, looks for sympathy, is demanding and selfcentered person, is emotionally excitable and feels very much upset to loose a game [23,24]. Lack of emotional maturity reduces people's ability to deal with anxiety, stress and frustration and causes problems. Studies have shown that joining social networks creates an ongoing reward to continue their application by causing feelings such as selfsatisfaction and self-efficacy. On the other hand, researchers believe that those who have little ability to establish social interactions tend to use social networks more than others in order to relieve the dysthymic state. Excessive use of internet with the aim of removing undesirable states causes some problems such as the risk of social isolation, increased psychological dependence on these networks, ignoring reallife relationships and work and training challenges.

Internet has become an integral part of the daily lives of most people, especially younger ager group after its introduction in early 1980. It has affected physical, social, emotional, mental and moral aspects of users' lives. According to social networks users' access to others emotional, intellectual and social situation, it is essential that these people become matured in different fields to be able to manage their thoughts and feelings if necessary and act purposefully. Therefore, according to the 
significance of the subject, is is important to examine the relationship between addiction to internet and emotional maturity and frustration intolerance.

\section{Review of Literature}

The variables in this study used by the researcher are frustration intolerance, emotional maturity and internet addiction among young adults. The review of literature is divided into three sections which are:

a. Section A: Review of literature and studies done upon frustration intolerance among young adults.

b. Section B: Review of literature and studies on emotional maturity among young adults.

c. Section C: Review of literature and studies done upon Internet Addiction among young adults.

\section{Section A: Frustration Intolerance among young adults}

Ellis [25] originally noted, in regard to frustration intolerance, that it is possible to "relate all forms of emotional disturbance to this problem", but for maximum usefulness these beliefs are best viewed as separate from self-worth beliefs (p. 30). Frustration intolerance referred to the demand for comfort and gratification, and ego disturbance to the demand that one must perform well, or gain approval, to achieve self-worth. More generally, it has been proposed that self-worth and frustration intolerance are characterized by different types of cognition (DiGiuseppe, 1996; Rorer, 1989). Thus, frustration intolerance represents the belief that reality should be how we want it to be, whilst ego disturbance is based on a definition of self-worth as dependent on meeting certain conditions.

Ellis [4] theorized that psychological disturbance arises, not only from threats to self-worth (ego disturbance), but also from intolerance of discomfort (discomfort disturbance). Such discomfort not only refers to negative emotions, but includes effort, everyday hassles, and a range of other frustrating events [2]. The alternative to frustration intolerance is the acceptance of reality, whilst retaining the desire for change. Other therapies in recent years have also emphasized the importance of acceptance. Thus, Dialectical Behavior Therapy (DBT) [26] has focused on distress tolerance, particularly in regard to borderline personality disorder. Similarly, Acceptance and Commitment Therapy (ACT) [27], has argued that psychological disturbance arises in large part from counterproductive control strategies resulting in experiential avoidance.

Harrington [28] found in his research on 242 participants explore the relationship between the four dimensions of frustration intolerance (emotional intolerance, demands for entitlement, comfort, and achievement) and problems of self-control. Results indicated that the Frustration Discomfort sub-scales showed differential relationships with self-control problems, independent of self-worth beliefs. Study provided evidence of the validity and usefulness of a multidimensional measure of frustration intolerance beliefs. The separate dimensions of frustration intolerance were differentially related to self-control problems, and showed unique relationships independent of selfworth beliefs. This highlights the importance of distinguishing between belief content dimensions, as well as between the processes of frustration intolerance and self-worth. It has neen identified in this study that once self-esteem had been accounted for, only demands for comfort had a unique relationship with procrastination. This finding is supported by research using a student population, which also showed comfort and self-esteem as unique predictors of procrastination [29].

Chih-Hung Ko, et al. [30] demonstrated that Internet addiction is associated with belief of frustration intolerance among adolescents. More attention and REBT should be focused on irrational beliefs of frustration intolerance for adolescents with Internet addiction. They evaluated the association between Internet addiction and frustration intolerance, the gender difference of frustration intolerance, and the gender differences of the association between Internet addiction and frustration intolerance. Females had higher scores on the subscale of entitlement and emotional intolerance and the total scale of the frustration intolerance. There was a significant gender difference on the association between Internet addiction and frustration intolerance. The association was higher in male adolescents. The findings also revealed that the male adolescents with Internet addiction had higher intolerance to frustration of entitlement and emotional discomfort, and female adolescents with it had higher intolerance to emotional discomfort and lower tolerance to frustration of achievement.

Sanda Stankovic, et al. [31] extended earlier research on relationship of the multidimensional Frustration Discomfort scale with measures of depressed mood, anxiety and anger, independent of self-esteem. The study was performed on non-clinical 323 students and measures of both state and trait anger and anxiety. The results indicated that dimensions of frustration Discomfort scale have differential relationship with dysfunctional emotions, independent of self-worth beliefs. There were predictive associations of entitlement with anger, emotional intolerance with anxiety, and discomfort intolerance with depressed mood were confirmed in this study and replicated in a nonclinical group. Emotional intolerance also proved to be a significant positive predictor of depression, whilst achievement frustration had a negative relationship with depression. Overall, the Frustration dimensions had a weaker relationship with emotional states than traits.

Pina Filippello, et al. [32] aimed to investigate the relationship between frustration intolerance and emotional-behavioural problems. Specifically, the study explored whether frustration intolerance beliefs were associated with difficulties in assertive behaviour, anxiety, depression, and anger in a non-clinical student sample $(\mathrm{N}=250)$. The findings supported a multidimensional model of frustration intolerance and the relationship between specific frustration intolerance beliefs and emotional-behavioural problems. Regarding unhealthy emotions, structural equation modeling (SEM) analyses (model A) indicated that discomfort intolerance and emotional intolerance had a significant relationship with state anxiety, trait anxiety, and depression. The discomfort intolerance and entitlement sub-scales had a significant relationship with state anger and trait anger, while entitlement directly predicted trait anger.

Jibeen $\mathrm{T}$ [33] studied to examine the role of unconditional self acceptance and self esteem in relation to frustration intolerance beliefs and psychological distress. The results showed the moderating effects of unconditional self acceptance and self esteem in the relationship between frustration intolerance beliefs (entitlement, achievement, emotional intolerance, and discomfort intolerance) and psychological distress. The findings highlighted the importance unconditional self acceptance that reduces the emotional problems of students hindering their educational and personal growth.

\section{Section B: Emotional maturity among young adults}

Hollingworth LS [11] mentions some characteristics of emotionally mature person as:

i. He is capable of responding in degree of emotional responses. He does not respond in all or none fashion, but Keeps within bounds.

ii. He is also able to delay his responses as controlled with the impulsiveness of young child.

iii. Handling of self pity, instead of showing unrestrained self pity, he tries to feel for him.

Therefore, emotionally mature is not one who necessarily has resolved all conditions that aroused anxiety and hostility but it is continuously in process of seeing himself in clearer perspective, continually involved in a struggle to gain healthy integration of feeling, thinking and action.

According to Walter D Smitson [34] emotional maturity is a process in which the personality is continuously striving for greater sense of 
emotional health both intra-psychically and intra-personally. Kalpan and Baron elaborate the characteristics of an emotionally mature person, is he has the capacity to withstand delay in satisfaction of needs. His focus is on long term planning and is capable of delaying or revising his expectations in terms of demands of situations.

Boyd NR, et al. [35] investigated the relationship between emotional maturity and drinking and driving involvement among adults was investigated. Analysis of data showed that among females and males in same age group, females are more emotionally mature than males; age is a factor in emotional maturity in that emotional maturity increases with age. It was concluded that a person with lower emotional is more likely to drive under the influence of alcohol.

As per Singh, et al. [36] emotional immaturity incorporates emotional instability i.e., individual lacking problem solving ability, will show irritability and seem to show temper tantrums and are more stubborn. The second dimension of emotional immaturity is emotional regression i.e., feeling of inferiority, restlessness, hostility, selfcenteredness, etc. the third dimension is social adjustment i.e., lack in social adaptability. The fourth dimension talks about personality integration which represent disintegration of personality, like reaction, phobias formation, rationalization, pessimism, immorality etc. the fifth dimension i.e., lack of independence shows parasitic dependence in a person.

Wadge \& Ganaie (2013) showed in their research less emotionally mature persons tend to prefer inefficient coping methods than that of useful methods and the more mature people prefer more efficient and useful methods. M. A.Durea amd M. H. Fertman (1941) conducted research on delinquent girls and findings showed that emotional immaturity was high. A study by Pandey and Amnibhavi (2006) on impact of emotional maturity on stress and self confidence found that adolescent with high emotional maturity have less stress and high confidence.

Chanda Rawat and Ritu Singh (2015) found in their study that adolescents from joint family background were significantly better on emotional progression, social adjustment, personality integration, and independent components of emotional maturity than those living in nuclear family.

Adolescents from joint families were noted to be righteous, contented, confident in social interaction and self-reliant, whereas those living in nuclear families were restless, had feeling of inferiority, hostility, were more aggressive, lacked in social adaptability, had phobia formation, were pessimist, immoral and were highly relying. On the whole, it can be concluded that family setup plays momentous role in overall development of adolescents.

Behera, et al. [37] examined the relationship between emotional maturity, self-esteem and life-satisfaction among traditional dancers. The results found that there was significant positive relationship between Emotional maturity and Life satisfaction. The result of the current investigation indicates that the importance of traditional dance to help positively life instincts. Both emotional maturity and self-esteem are associated with life satisfaction. Emotional factors positively account life satisfaction through the moderator self-esteem. Gradually it is building many kinds of literacy while developing intuition, reasoning, imagination, healthy, self-esteem, selfconfidence, self-image and emotional maturity into unique forms of expression and communication. Both physically and psychologically it contributes positive well-being as well as provides life satisfaction. Further research is required in this area.

\section{Section C: Internet addiction among young adults}

Since 1996, many studies have examined Internet addiction, exploring the relationships among heavy Internet use, social-psychological factors, and computer-related factors. The terms "overuse" and "excessive use," which appear in many Internet addiction studies, usually indicate that time online is an important factor or index for determining Internet addiction. Young's study (1998), Internet dependents reported a striking average of $39 \mathrm{hr}$ per week spent online, compared to the $5 \mathrm{hr}$ of non-dependents. In other words, dependents spent the equivalent of a "full-time job" on the Internet and spent nearly 8 times the number of hours per week online than did non dependents.

Similarly, Chen and Chou (1999) reported that the Internet addiction "high-risk" group spent significantly more time online than the non-high-risk group. Whereas the high-risk group spent an average of $20 \mathrm{hr}$ per week online, the non-high-risk group spent about 9 $\mathrm{hr}$ online. The results also indicated that students' scores on their Chinese Internet Addiction Scale were significantly correlated with their weekly Internet-use hours. Similar results were found in Chou and Hsiao's study (2000): about 54 (6\%) Internet addicts spent 20$25 \mathrm{hr}$ per week online, almost triple the number of hours that 856 non-addicts spent online. Online activities or applications (such as chat rooms or online games) are also an important factor used in determining Internet addiction, in Young's study (1998), dependents used predominately two-way communication functions such as chat rooms, role-playing games (e.g., Multi-User Dungeons or Multi-User Dimensions, also known as MUDs), newsgroups, or email, whereas non-dependents most likely used information-gathering functions available on the Internet such as Information Protocols and the World Wide Web (WWW).

Young concludes that although the Internet itself is not addictive, specific applications appear to play a role in the development of pathological Internet use. Young's conclusion is consistent with Kandell's observation that MUD games, Internet relay chat (IRC), and chat rooms are the primary Internet activities that lead to addictive behavior. Extended Web surfing and compulsively checking email can also create overuse problems. In an Asian culture context, Chou et al. (1999) reported that some Taiwan college students who were considered "addicts" most frequently used the chat and talk functions of electronic Bulletin Board Systems (BBSs), followed by use of the WWW, File Transfer Protocol, Newsgroups, email, and games. In a later study (Chou and Hsiao, 2000), researchers found that members of an addicted group spent more time on BBSs and email than did members of a non-addicted group. Furthermore, the addicted group also spent more time on the WWW than did the non-addicted group. This study reported that the number of hours spent using BBSs and email are predictors for determining Internet addiction. The work of Young (1998), Chou et al. (1999), and Chou and Hsiao (2000) empirically confirms that Internet addicts use two-way communication functions more than nonaddicts do.

Brenner [38] in his study, $80 \%$ of nearly 600 respondents indicated at least five use-related problems such as failure to manage time, missed sleep, missed meals, etc., suggesting that such patterns are the norm. Some respondents reported more serious problems because of Internet use: trouble with employers or social isolation except for Internet friends-troubles similar to those found with other addictions.

Scherer's [39] indicated that $13 \%$ of respondents reported that Internet use had interfered with either their academic work, professional performance, or social lives. Among them, about $2 \%$ perceived the Internet as having an overall negative effect on their daily lives. Similarly, in Young's study (1998), dependents reported that excessive use of the Internet resulted in personal, family, and occupational problems similar to those experienced in other addictions. Chief among these problems was time distortion, which even resulted in some physical complaints such as disrupted sleep patterns and fatigue. Students may also experience profound academic problems, eventually resulting in poor grades, academic probation, and even expulsion from universities. Other problems created by excessive Internet use include disrupted marriages, financial problems, and relationship problems (sexual/romantic, parent-child, and friendship 
problems). Based on the aforementioned studies, it is difficult to draw the conclusion that heavy use of the Internet results in an overall negative impact on addicts' lives; only one negative impact can be conclusively identified: time-disruption, leading to interference with academic work, professional performance, daily routines, and so on. However, findings on the impacts of heavy Internet use on addicts' social relationships are inconclusive to positive.

Scherer [39] reported that dependent Internet users included a significantly larger proportion of men to women (71\% men and $29 \%$ women, respectively) than the non-dependent users $(50 \%$ are men and women).

Young [14] concludes that the Internet itself is not addictive, but specific applications embedded within interactive features play a significant role in the development of pathological Internet use. Griffiths argues that the structural characteristics of particular activities are responsible for reinforcement, may satisfy users' needs, and may actually facilitate excessive or pathological use. Structural characteristics, in his words, refer to the features that manufacturers design into their products.

Grohol suggests that societal acceptance and promotion of the Internet must also be considered. If most of the information we need in our daily lives (e.g., from mass media) can be easily and cheaply obtained from the Internet, and if activities (e.g., writing letters, making phone calls) can also be carried out from the Internet, then it is no leap to predict that more and more people will spend more and more time online.

Morahan-Martin, et al. [40] reported that males were more likely than females to be pathological users ( $12 \%$ vs. $3 \%)$, whereas females were more likely than males to have no symptoms ( $28 \%$ vs. $26 \%)$ or have limited symptoms (69\% vs. 61\%) of behavioural pathology. The notion that males, or at least male college students, are more subject to Internet addiction has empirical support.

Chou and Hsiao (2000) conducted a larger-scale investigation focused not only on pleasure experience but also on the use gratification aspect of Internet use. This study collected 910 valid survey responses from 12 universities and colleges around Taiwan and identified about $6 \%$ of respondents as Internet addicts. The results indicated that the addict group found the Internet entertaining, interesting, interactive, and enjoyable. The study also found that the most powerful predictor of Internet addiction was the communication pleasure score, followed by BBSs use hours, gender, satisfaction (gratification) score, and emailuse hoursIf we understand the Internet as a kind of mass medium, then the possibility surfaces that the Internet is in the process of replacing or substituting for a part of traditional media (e.g., television, radio, newspapers, magazines, books, and so on) (Chou, 2001).

\section{Rationale}

According to Internet world Stats, there are currently 4.54 billion active internet users in present time. Despite the benefits there is growing evidence that the addiction to internet is adversely affecting the mental health and well-being of users. Internet provides immediate reinforcement, when facing stressful events in daily life, beliefs of frustration intolerance may make adults unwilling to tolerate negative emotional events, and may make users to escape from the unacceptable frustrations of daily life and seek immediate gratification from the internet. Frustration intolerance being a core irrational belief in Rational emotive behavioural therapy causing psychological disturbance and maladaptive behaviours. Frustration intolerance explain the unwillingness to tolerate negative emotional events causing distress and discomfort. A person would indulge in escaping these stressful events and may seek gratification from internet which is easily accessible. One of the characteristics of emotional maturity is that the person has the capacity to withstand delay in satisfaction of needs and the ability to tolerate reasonable amount of frustration. These factors may make a person more vulnerable to internet addiction.
There has been many researches in area of frustration intolerance and its relation to emotional dysfunction, unhealthy emotions and other maladaptive behaviour pattern. As a researcher with background in psychology and training in rational emotive behaviour therapy, it gave me an opportunity to study the effects of frustration intolerance belief on internet addiction and what REBT core belief of frustration intolerance has to play in maladaptive behaviour of internet addiction. This research may help counsellors and psychotherapist to deal with frustration intolerance of a person with internet addiction.

The main purpose of studying emotional maturity role in internet addiction as emotional maturity is considered to be one of the major component in emotional and mental wellbeing. Although, currently there is no existence of a specific diagnosis of internet addiction as a disorder but various researches has been conducted on internet addiction. One of the characteristics of emotional maturity is that the person has the capacity to withstand delay in satisfaction of needs and the ability to tolerate reasonable amount of frustration. These factors may make a person more vulnerable to internet addiction.

\section{Method of Study}

\section{Purpose}

a. To find the effect of frustration intolerance on internet addiction among young adults.

b. To find the effect of emotional maturity on internet addiction among young adults.

c. To seek the difference between male and female mean for each variable i.e., frustration intolerance, emotional maturity and internet addiction.

\section{Objective}

The objective was to see how the irrational belief of frustration intolerance present in an individual impacts internet addiction among young adults.

The objective was to see how the emotional maturity in a person can effect maladaptive behaviour pattern of internet addiction among young adults.

\section{Research design}

The research design used was Ex post Facto as it examines how an independent variable present prior to the study affects the dependent variable.

\section{Variables}

\section{Independent variable}

Frustration intolerance: Albert Ellis viewed frustration intolerance or the inability to tolerate frustration and discomfort is a main feature of psychological disturbance. It is considered as the demand for comfort and gratification.

Emotional maturity: Walter D Smitson [9] describes emotional maturity is the process in which the personality is continually striving for greater sense of emotional health, both intra-psychically and intrapersonally.

\section{Dependent variable}

Internet addiction: The Internet Addiction Test [14] was developed to measure the presence and severity of Internet and technology dependency among adults. As a growing cultural and clinical phenomenon, Internet Addiction is viewed as a new clinical disorder requiring assessment and treatment.

\section{Tools}

Frustration discomfort scale: This scale was developed by Neil Harrington [41] to asses irrational core belief of frustration intolerance. 
It consists of 28 statements with four sub-scales of 7 items: discomfort intolerance, entitlement, emotional intolerance and achievement. Respondents rate the strength of belief on a 5-point Likert-type scale with the following anchors: (1) absent, (2) mild, (3) moderate, (4) strong, (5) very strong. Higher scores indicate greater frustration intolerance. The Cronbach's alphas were 0.84 to 0.88 . The revised subscales showed unique relationships with specific psychological problems and evidence of convergent and divergent validity. In this presenting study, its Cronbach's alphas of total scale and subscales were 0.78 to 0.93 . The FDS has good evidence of reliability (Cronbach's score shows .94 reliability for the full scale) with acceptable coefficient alphas for the respective sub-scales: $.88, .85, .87$, and .84 .

Emotional maturity scale: Emotional Maturity Scale was developed by Singh Y, et al. [42]. This scale measures a list of five broad factors of Emotional Immaturity - Emotional Unstability, Emotional regression, social maladjustment, personality disintegration and lack of independence. It is a self-reporting five point scale. Items of the scale are in question form demanding information for each in any of the 5 options: Always, Mostly, Uncertain, Usually, Never. The items were scored as 5, 4, 3, 2 and 1 respectively. Therefore, the higher the score on the scale leads greater the degree of emotional immaturity and vice versa. The scale has total 48 items. There are 10 items per factor except the fifth factor which has 8 items. The highest possible score for the first 4 areas are 50 and the lowest is 10 while for the fifth factor the highest score is 40 and lowest is 8.(For all the first 4 factors the extremely unstable range from 10-20 ( for 5th factor-8-16), moderately unstable from 21-30 (17-24), unstable from 31-40 (2532 ), stable from 41-50(33-40). Reliability of the scale was determined by test retest reliability which was 0.75 and internal consistency for various factors ranged from .42-.86. The scale was validated against external criteria, i.e. the area of the adjustment inventory for college students (Sinha and Singh, 1995).

Internet addiction test: Which developed by Kimberly Young in 1998 to determine how children perceive themselves about internet addiction. For the adopted scale, reliability coefficient Cronbach alpha was calculated as 0.90 and Spearman Brown value was calculated as 0.86 . Exploratory factor analysis was used to confirm the construct validity, and confirmatory factor analysis used to determine whether the factor model was correct. As a result of this analysis, it was determined that 20 items were grouped under 4 factors. Cronbach $\alpha$ , internal consistency coeficient for the first factor was 0.91; second factor was 0.87; third factor was 0.89 , fourth factor was 0.90 ; and for the whole scale was 1.90. Spearman Brown value for the scale was 0.86 Guttmaan Split-Half value for the scale was 0.85 . These calculated coefficients were all in the acceptable range, and these suggested that the test and the each factor had internal reliability. Validity and reliability analysis were reviewed about the adoption- of Internet Addiction Test and it was concluded that the results that were found was in the acceptable ranges.

\section{Sample}

The sample size was a group of 100 young adults both boys ang girls in the age range 18 to 25 years through incidental sampling.

\section{Procedure}

The instructions were read carefully by the researchers and the purpose was mentioned clearly to the participants. All the three above mentioned i.e., Frustration Discomfort Scale, Emotional Maturity Scale, The Internet Addiction Test, were then distributed to the students of age 18-25. The participants responded successfully and questionnaire were presented in an orderly manner and proper time was given to the respondents. Headings of each scales were removed before presenting the questionnaire to the respondents and based on this a target sample size of 100 was contacted for the purpose of collecting the data. It was made sure that the room was free from any disturbances, noise and distractions. There was no time limit given to the respondents but it took 30-40 minutes to fill all the questionnaire and the researcher was available for the respondent's doubts regarding the questionnaire. After the data collection, it was analysed through SPSS using t-test and two way ANNOVA, the findings were reported to the respondents who were interested to know the results.

\section{Results}

Use of statistical test for analysis and interpretation of all collected data through the large sample size was done using the statistical tool twoway ANNOVA and t-test using SPSS software.

The above Table 1 shows the analysis of variance i.e., two way ANOVA of given variables. The results shows that there is statistically significant difference of emotional maturity on dependent variable internet addiction as its value i.e., 0.004 is much lower than selected $p$ value of 0.05 . And there is also statistically significant difference of frustration intolerance on dependent variable internet addiction as its value i.e., 0.000 is much lower than selected p value of 0.05 . But the interactional effect of both emotional maturity and frustration intolerance on internet addiction is not found to be significant as its value is greater than selected $\mathrm{p}$ value. This means that null hypothesis is rejected the case of emotional maturity and frustration intolerance. This shows that there is significant effect of emotional maturity on internet addiction. And the observed $\mathrm{p}$ value of 0.000 shows that frustration intolerance has significant effect on internet addiction. In the interactional effect the observed $p$ value of 0.602 shows that the probability of occurring combined effect of frustration intolerance and emotional maturity on internet addiction, by chance can be attributed to $60.2 \%$. since selected $\mathrm{p}$ value is 0.05 so there is no interactional effect of both the variable on internet addiction.

Table 1: Showing effect of frustration intolerance and emotional maturity on internet addiction.

\begin{tabular}{|c|c|c|c|c|c|}
\hline Source & $\begin{array}{c}\text { Type I Sum of } \\
\text { Squares }\end{array}$ & df & $\begin{array}{c}\text { Mean } \\
\text { Square }\end{array}$ & F & Sig. \\
\hline EIM & 1150.027 & 1 & 1150.027 & 8.692 & 0.004 \\
\hline FIS & 4478.447 & 1 & 4478.447 & 33.849 & 0 \\
\hline EIM ${ }^{*}$ FIS & 36.214 & 1 & 36.214 & 0.274 & 0.602 \\
\hline
\end{tabular}

${ }^{*} \mathrm{p} \tilde{0} 0.05$

The above Table 2 shows descriptive statistics for each variable showing mean and standard deviation of frustration intolerance, emotional maturity and internet addiction among young adults. The sample size of both male and female are equal $(\mathrm{N}=50)$. The result table shows that the average amount or the mean value for frustration intolerance among male young adult is 84.88 and for female young adult is 81.44 which shows the moderate level of frustration intolerance in both the gender. And the average amount or the mean value for emotional maturity among male young adult is 126.40 and for female young adults is 121.96 which shows the extreme emotional immaturity with standard deviation of 25.08 for male and 22.331 for female. The average amount or the mean value for internet addiction among male young adult is 70.86 and for female young adults is 68.58 which shows the moderate level of internet usage with standard deviation of 13.41 for male and 13.867 for female young adults. It can be interpreted that there is slight differences observed in mean and standard deviation among male and female young adults.

The result Table 3 shows the independent sample t-test using Levene's Test for Equality of Variances and shows t-test for equality of means. The table shows the differences of distribution of scores on the basis of gender for each variable. The significance value or $p$ value selected is less than 0.05 . The table shows that the observed significance value of all the variable is much higher than selected significance value which means that each value is much higher than 0.05 . So the null hypothesis here in each variable is accepted and it is assumed that variances are 
approximately equal. The significance value (2-tailed) of each variable is observed to be higher than level of significance (0.05) i.e., 0.246, 0.352 and 0.405 of frustration intolerance, emotional maturity and internet addiction. The higher value of significance value observed shows that the null hypothesis is accepted i.e., the mean score between the groups of male and female for each variable is not significantly different. It can be interpreted from the result table 3 that the mean score for each variable is approximately the same.

Table 2: Showing the comparision of mean of variables on the basis of gender.

\begin{tabular}{|c|c|c|c|c|c|}
\hline & Gender & $\mathbf{N}$ & Mean & Std. Deviation & Std. Error Mean \\
\hline \multirow{2}{*}{ Frustration Intolerance } & male & 50 & 84.88 & 16.211 & 2.293 \\
\cline { 2 - 6 } & female & 50 & 81.24 & 14.947 & 2.114 \\
\hline \multirow{2}{*}{ Emotional Maturity } & male & 50 & 126.4 & 25.08 & 3.547 \\
\cline { 2 - 6 } & female & 50 & 121.96 & 22.331 & 3.158 \\
\hline \multirow{2}{*}{ Internet Addiction } & male & 50 & 70.86 & 13.412 & 1.897 \\
\cline { 2 - 6 } & female & 50 & 68.58 & 13.867 & 1.961 \\
\hline
\end{tabular}

Table 3: Shows independent sample t- test.

\begin{tabular}{|c|c|c|c|c|c|c|c|c|}
\hline \multirow{2}{*}{ Variables } & & \multirow{2}{*}{$\mathbf{F}$} & \multirow{2}{*}{ Sig. } & \multirow{2}{*}{$\mathbf{t}$} & \multirow{2}{*}{ df } & \multirow{2}{*}{$\begin{array}{c}\text { Sig. } \\
\text { (2-tailed) }\end{array}$} & \multicolumn{2}{|c|}{$95 \%$ Confidence interval of the difference } \\
\hline & & & & & & & Lower & Upper \\
\hline \multirow[t]{2}{*}{ FI } & $\begin{array}{c}\text { Equal variances } \\
\text { assumed }\end{array}$ & 1.027 & 0.313 & 1.167 & 98 & 0.246 & -2.548 & 9.828 \\
\hline & \multicolumn{3}{|c|}{ Equal variances not assumed } & 1.167 & 97.361 & 0.246 & -2.549 & 9.829 \\
\hline \multirow[t]{2}{*}{ EM } & $\begin{array}{c}\text { Equal variances } \\
\text { assumed }\end{array}$ & 0.442 & 0.508 & 0.935 & 98 & 0.352 & -4.984 & 13.864 \\
\hline & \multicolumn{3}{|c|}{ Equal variances not assumed } & 0.935 & 96.707 & 0.352 & -4.986 & 13.866 \\
\hline \multirow[t]{2}{*}{ IAT } & $\begin{array}{c}\text { Equal variances } \\
\text { assumed }\end{array}$ & 0.001 & 0.97 & 0.836 & 98 & 0.405 & -3.134 & 7.694 \\
\hline & \multicolumn{3}{|c|}{ Equal variances not assumed } & 0.836 & 97.891 & 0.405 & -3.134 & 7.694 \\
\hline
\end{tabular}

*p $0 \tilde{0} 0.05$

${ }^{* *} \mathrm{p} \tilde{0} 0.05$

\section{Discussion}

The study was designed to evaluate effect of frustration intolerance and emotional maturity on internet addiction. This research was carried out as a study on young adults over the age of 18 years till the age of 25 years, at the same time. It was conducted on 50 male young adults and 50 female young adults to compare the means of each variable i.e., frustration intolerance, emotional maturity and internet addiction. The research revealed that the inability in tolerating frustration or distress experienced on the daily basis has its effect on internet addiction. As well as the emotional maturity or the ability to regulate emotions with delay in satisfaction or immediate gratification can impact on internet usage level.

According to the "ABCDE" model of REBT, when facing an activating event, the irrational belief will cause the dysfunctional consequence. Many researches have shown that frustration intolerance is associated with behaviour avoidance. Because internet provides immediate reinforcement such as a feeling of control, online interaction with others private, group or addressing the many people at the same time, and the freedom of self-representation, when facing distressing events in real life, beliefs of frustration intolerance may make young adults unwilling to tolerate negative emotional events, and they may be more likely to escape from the unaccepted frustrations of daily life and seek immediate gratification from the Internet and become vulnerable to internet addiction. On the other hand, since many of young adults experience the internet early in life, immediate reinforcement provided by the internet might also influence their beliefs. If pleasure could always be experienced without coping with frustration online, longterm exposure to Internet activity may also make young adult believe that life should be as comfortable as it is in Internet. Without effective intervention for such beliefs, these young adults may prefer Internet activity and enter a vicious cycle. However, the causal relationship between frustration intolerance and Internet addiction should be further clarified by future study.

The results in Table 2 \& Table 3 also revealed that there was no gender difference observed in internet usage as well as the frustration intolerance. The mean of both the groups were approximately same and through $t$ test it was identified that there were no differences in the mean of both the genders. Though the frustration intolerance mean of female was slightly higher than females. And the internet addiction mean score of male young adults were slightly higher than female young adults. Although the study conducted by $\mathrm{Ko} \mathrm{CH}$, et al. [43-47] on adolescent have shown that the frustration intolerance is associated with Internet addiction and is higher among female adolescents, Internet addiction is more prevalent in males. Further analysis in this study revealed that gender was a moderator for the association between frustration intolerance and Internet addiction. It demonstrated that frustration intolerance is more associated with Internet addiction for males. The gender difference of coping style may explain the higher impact on male adolescents. It has been reported that male adolescents are more likely than female adolescents to use avoidance strategies and emotional distraction coping. The result of this study also revealed that female adolescents are more likely to hold the belief of intolerance to emotional distress and unfairness. It has been reported that female adolescents worry more about lack of confidence issues. This may contribute to their belief for entitlement. Female adolescents also have a more negative problem orientation and engage in more thought suppression. This may result in more emotional distress, such as depression and anxiety, which have been reported to be more prevalent in female adolescents. This prevalence may be associated with their emotional intolerance belief. Hill, et al. [48] have argued that the gender role for female adolescents brings 
conflict over achievement and results in depression because of fears that success will be perceived as unattractive and because of heightened self-consciousness over physical appearance. The conflict associated with the gender role might also account for their belief of entitlement and emotional intolerance. Since the data collected from the sample shows slight difference between male and female but that does not completely explain the mean difference of population on the basis of gender in internet usage as well as frustration intolerance.

The Table 2 shows the sample mean of emotional maturity were approximately the same and no significant differences in emotional maturity level on the basis of gender was observed. Although the sample mean of male was slightly higher than that of female. mean of both the gender from the collected sample have shown the extreme level of emotional immaturity. Also the level of emotional immaturity was slightly higher in male than in female. The study conducted by Seema Bajaj and Sukhjot Roy (2019) on gender differences in emotional maturity among adolescents with sample of 100 males and 100 female. It was concluded that gender does not play a significant role in determining the emotional maturity among young adults.

The result Table 1 have shown significant effect of emotional maturity on internet addiction. One of the characteristics of emotional maturity is that the person have the capacity to withstand delay in satisfaction of needs and the ability to tolerate reasonable amount of frustration. These factors may make a person more vulnerable to internet addiction.

\section{Conclusion}

This study demonstrates that Internet addiction is associated with belief of frustration intolerance among adolescents. More attention and REBT should be focused on irrational beliefs of frustration intolerance for young adults with Internet addiction. Intolerance to emotional discomfort should be emphasized in REBT for both male and female young adults with Internet addiction, and the irrational belief of entitlement intolerance should be highlighted for male as well as female young adults with Internet addiction. Further intervention research is necessary to evaluate the effect of REBT for Internet addiction among young adults.

Further conclusions that can be drawn from the study that emotional maturity had an effect on internet addiction. The delay of immediate gratification, ability to regulate ones emotions has to be focused on young adults with problematic usage of internet. No gender differences has been observed in every variable has been observed so the irrational belief of frustration intolerance, emotional immaturity and internet addiction has to be equally addressed in both male as well as female young adults.

\section{Limitations and Suggestions}

Certain limitations were seen during the study and can be taken into consideration. On the one hand, because the sample size was small we should be careful when looking at the results.

All our investigations relied on self-reported data from adolescents. The sample mean of the present study could not completely explain population mean. The effect of independent variable did not show how much impact they made on dependent variable i.e., internet addiction among young adults.

Suggestions that can be made are that the irrational belief of frustration intolerance can be addressed among young adults while dealing with internet addiction. Distress tolerance as well as emotional regulation techniques could be used while dealing with internet addiction as high level of emotional immaturity was observed from the data collected in both male as well as female young adults.

\section{Acknowledgement}

None.

\section{Conflicts of interest}

The author acknowledges that there is no conflict of interest.

\section{References}

1. Ellis A. Rational-emotive therapy: Research data that support the clinical and personality hypotheses of RET and other modes of cognitivebehavior therapy. In: A Ellis \& JM Whiteley (Eds.). Theoretical and empirical foundations of rational-emotive therapy. pp: 101-173; 1979a.

2. Dryden W (1999) Rational Emotive Behavioural Counselling in Action. $2^{\text {nd }}$ edn. London: Sage.

3. Beal D, Kopec AM, DiGuiseppe R (1996) Disputing clients' irrational beliefs. J Rational-Emot Cognitive-Behav Ther 14:215-229.

4. Ellis (1979), Harrington, N. Frustration Intolerance: Therapy Issues and Strategies. J Rat-Emo Cognitive-Behav Ther 29:4-16.

5. Ellis A, Dryden W (1987) The practice of rational emotive therapy. New York: Springer.

6. Krantz SE, Moos RH (1988) Risk factors at intake predict nonremission among depressed patients. Journal of Consulting and Clinical Psychology 56(6):863-869.

7. DiBartolo PM, Frost RO, Chang P, LaSota M, Grills AE (2004). Shedding light on the relationship between personal standards and psychopathology: The case for contingent self-worth. Journal of Rational-Emotive \& Cognitive-Behavior Therapy 22(4):237-250.

8. Frost RO, Marten P, Lahart C, Rosenblate R (1990) The dimensions of perfectionism. Cognitive Therapy and Research 14(5):449-468.

9. Smitson WS (1974) The meaning of emotional maturity. MH: Winter. 58: 9-11.

10. Kaplan and Baron (1986) Status quo of Emotions and Emotional behaviour. Retrieved from wikieducator.org/Status quo of Emotions and Emotional behaviour.

11. Hollingworth LS (1928) Colour Preference and Emotional Maturity.

12. Mohsin SM (1960) A measure of emotional maturity. Psychological Studies. 5(2): 78-83.

13. Rao TV, Stewart AJ (1976) Stewart Maturity Scale (Indian Adaptation). New Delhi: Manasayan.

14. Young KS (1998) Caught in the Net: How to recognize the signs of Internet addiction and a winning strategy for recovery. New York: John Wiley.

15. Yellowlees PM, Marks S (2007) Problematic Internet use or Internet addiction? Computers in Human Behavior 23(3): 1447-1453.

16. Block JJ (2008) Issues for DSM-V: Internet addiction. The American Journal of Psychiatry 165(3): 306-307.

17. Albrecht U, Kirschner NE, Grusser SM (207) Diagnostic instruments for behavioral addiction: An overview. Psycho Soc Med 4:1-11.

18. Soule LC, Shell LW, Kleen BA (2003) Exploring Internet addiction: Demographic characteristics and stereotypes of heavy Internet users. Journal of Computer Informational System 44(1): 64-73.

19. Song I, Larose R, Eastin MS, Lin CA (2004) Internet Gratifications and Internet Addiction: On the Uses and Abuses of New Media. Cyber Psychol Behav 7(4): 384-394.

20. Morahan Janet, Schumacher P (2000) Incidence and Correlates of Pathological Internet Use Among College Students. Computers in Human Behavior 16(1): 13-29.

21. Young KS (2004) Internet addiction: a new clinical phenomenon and its consequences. American BeckBehavioural 48(4): 402-415.

22. Young K (1998) Internet Addiction Test.

23. Cattell RB (1945). The description of personality: principles and findings in a factor analysis. The American Journal of Psychology 58(1): 69-90.

24. Brogden HE (1944) A multiple-factor analysis of the character trait intercorrelations published by Sister Mary McDonough. Journal of Educational Psychology 35(7): 397-410.

25. Harrington N (2011) Frustration Intolerance: Therapy Issues and Strategies. Journal of Rational-Emotive \& Cognitive-Behavior Therapy 29: 4-16. 
26. Linehan MM (1993) Cognitive Behavioral Treatment of Borderline Personality Disorder. New York: Guilford Press.

27. Hayes SC (1999) Strosahl K, Wilson KG. Acceptance and commitment therapy: An experiential approach to behavior change. New York: Guilford Press.

28. Harrington N (2005) Dimensions of frustration intolerance and their relationship to self-control problems. Journal of Rational-Emotive and Cognitive-Behaviour Therapy 23: 1-20.

29. Harrington N (2005) The Frustration Discomfort Scale: development and psychometric properties. Clinical Psychology Psychotherapy 12: 374-387.

30. Chih-Hung Ko, Ju-Yu Yen, Cheng-Fang Yen, Chung-Sheng Chen, ShingYaw Wang (2008) The Association between Internet Addiction and Belief of Frustration Intolerance: The Gender Difference. Cyberpsychol Behav 11(3): 273-278.

31. Stanković S, Vukosavljevic-Gvozden T (2011) The Relationship of a Measure of Frustration Intolerance with Emotional Dysfunction in a Student Sample. Journal of Rational-Emotive \& Cognitive-Behavior Therapy 29: 17-34.

32. Filippello P, Harrington N, Buzzai C, Sorrenti L (2018) Perceived parental psychological control and school learned helplessness: The role of frustration intolerance as a mediator factor. School Psychology International 39(4): 360-377.

33. Jibeen $\mathrm{T}$ (2017) Unconditional Self Acceptance and Self Esteem in Relation to Frustration Intolerance Beliefs and Psychological Distress. J Rat-Emo Cognitive-Behav Ther 35: 207-221.

34. Poonam Dhaka, Antonia Shitilitha Mukwiilongo (2020) Emotional maturity assessment of children living in residential homes in Namibia. Emotional and Behavioural Difficulties 25(1): 3-14.

35. Boyd NR, Huffman WJ (1984) The relationship between emotional maturity and drinking-and-driving involvement among young adults. Journal of Safety Research 15(1): 1-6.

36. Srinivasan R, N Pugalenthi (2019) A Study on Relationship Between Emotional Maturity and Teaching Competency of Prospective Teachers. Shanlax International Journal of Education 7(4): 42-45
37. Behera S, Rangaiah B (2017) Relationship between emotional maturity, self-esteem and life-satisfaction: A study on traditional dancers of Odisha region. Cogent Psychology 4(1).

38. Brenner V (1997) Psychology of computer use: XLVII. Parameters of Internet use, abuse and addiction: the first 90 days of the Internet Usage Survey. Psychological reports 80(1): 879-882.

39. Chou C, Condron L, Belland J (2005) A Review of the Research on Internet Addiction. Educational Psychology Review 17(4): 363-388.

40. Morahan Martin J (2005) Internet Abuse: Addiction? Disorder? Symptom? Alternative Explanations? Social Science Computer Review 23(1).

41. Harrington N (2005) Dimensions of frustration intolerance and their relationship to self-control problems. Journal of Rational-Emotive and Cognitive-Behavior Therapy 23: 1-20.

42. Singh Y, Bhargava M (1991) Emotional Maturity Scale (EMS). Applied and community Psychology.

43. Ko CH, Yen JY, Chen CC, Chen SH, Yen CF (2005) Gender differences and related factors affecting online gaming addiction among Taiwanese adolescents. J Nerv Ment Dis 193(4): 273-277.

44. Ko CH, Yen JY, Chen CC, Chen SH, Yen CF (2005) Proposed diagnostic criteria of Internet addiction for adolescents. J Nerv Ment Dis 193(1): 728-733.

45. Ko CH, Yen JY, Chen CC, Chen SH, Wu K, et al. (2006) Tridimensional personality of adolescents with Internet addiction and substance use experience. Can J Psychiatry 51(14): 887-894.

46. Ko CH, Yen JY, Yen CF, Chen CC, Yen CN, et al. (2005) Screening for Internet addiction: an empirical research on cut-off points for the Chen Internet Addiction Scale. Kaohsiung J Med Sci 21(12): 545-551.

47. Chih-Hung Ko (2008) Brain activities associated with gaming urge of online gaming addiction. J Psychiatr Res 43(7):739-747.

48. Priess HA, Lindberg SM, Hyde JS (2009) Adolescent gender-role identity and mental health: gender intensification revisited. Child Dev 80(5):1531-1544. 